\title{
SELEÇÃO E FORMAÇÃO DE TRABALHADORES FRENTE À COVID-19: TECITURA E DIÁLOGOS ENTRE TRABALHO E EDUCAÇÃO NA SAÚDE
}

SELECTION AND TRAINING OF WORKERS TO FACE COVID-19: TISSUE AND DIALOGUES BETWEEN WORK AND HEALTH EDUCATION

SELECCIÓN Y FORMACIÓN DE TRABAJADORES FRENTE A LA COVID-19: CRUCES Y DIÁLOGOS ENTRE TRABAJO Y EDUCACIÓN EN LA

SALUD

Marcia Maria Santos da Silva ${ }^{1}$

Karina Oliveira de Mesquita 2

Fabrícia Rocha de Meneses Farias 3

Francisco Elder Escossio Barros 4

José Clauber Matos Brayner ${ }^{5}$

Maria José Galdino Saraiva 6

Palavras-chave:

Seleção de pessoal; Educação; Capacitação de recursos humanos em saúde; Educação interprofissional; Práticas interdisciplinares.

Keywords:

Personnel selection; Education;

Training of human resources in health; Interprofessional education; Interdisciplinary practices.

Palabras clave: Selección de personas; Educación; Capacitación de recursos humanos en salud; Educación interprofesional; Prácticas interdisciplinares.

Submetido: $17 / 11 / 20$

Aprovado: $27 / 12 / 20$

Autor(a) para Correspondência: Márcia Maria Santos da Silva R. Santana do Acaraú, 280 Pedro Mendes Carneiro Sobral - CE CEP: 62030-712

E-mail:marciamss@yahoo.com.br

\section{RESUMO}

Este manuscrito objetiva descrever a experiência de educação, no âmbito da saúde, desenvolvida pela Secretaria da Saúde de Sobral, por meio da Escola de Saúde Pública Visconde de Saboia, durante a pandemia de Covid-19. Tratase de um relato de experiência realizada no município de Sobral, de março a outubro de 2020, a qual contemplou a qualificação das atividades de gestão do trabalho e da educação na saúde, por meio de processos seletivos e formação de profissionais para atuar na prevenção e tratamento da Covid-19. Evidenciouse que foi fundamental a definição de perfis coerentes com as estratégias de gestão e cuidado em saúde, fomentando a realização de processos seletivos para categorias profissionais que atuam em diferentes níveis da atenção. A qualificação dos trabalhadores englobou diversas categorias profissionais e diferentes níveis de formação, promovendo uma prática interprofissional e colaborativa. Aponta-se a relevância desta experiência, sobretudo em situações relacionadas ao enfrentamento de problemas de saúde pública em caráter de urgência, considerando-o um disparador de reflexões sobre as novas formas de se fazer saúde e se (re)inventar em situações diversas.

1. Assistente Social. Mestre em Ensino na Saúde (UECE). Gerente da Célula de Ensino e Pesquisa na Escola de Saúde Pública Visconde de Saboia(2017-2020). E-mail: marciamss@yahoo.com.br ORCID: https://orcid.org/0000$\underline{0001-6534-8196}$

2. Enfermeira. Mestre em Saúde da Família (UFC). Docente na Escola de Saúde Pública Visconde de Saboia. E-mail: karinamesquita1991@gmail.com 0RCID: https://orcid.org/0000-0003-1528-5339

3. Bacharela em Ciências da Computação. Especialista em Educação a Distância (UFC). Operadora de rede de teleprocessamento na Escola de Saúde Pública Visconde de Saboia. E-mail: fabriciamenezes@gmail.com 0RCID: https://orcid.org/0000-0002-9103-8973

4. Contador. Mestre em Administração (UNIVALE). Coordenador Administrativo Financeiro na Escola de Saúde Pública Visconde de Saboia. E-mail: elderescossio@hotmail.com ORCID: https://orcid.org/0000-0001-8185-9199 5. Advogado. Mestre em Saúde da Família (UFC). Gerente de Editais e Projetos da Secretaria Municipal da Saúde de Sobral(2017-2020). E-mail: clauberbrayner@hotmail.com ORCID: https://orcid.org/0000-0001-7810-9856

6. Pedagoga. Mestre em Ensino na Saúde (UECE). Coordenadora Pedagógica na Escola de Saúde Pública Visconde de Saboia. E-mail: mariajosegaaldinosaraiva@gmail.com 0RCID: https://orcid.org/0000-0001-6006-9091 


\section{ABSTRACT}

This manuscript aims to describe the education experience, in the scope of health, developed by the Health Department in Sobral, through the Escola de Saúde Pública Visconde de Saboia (ESP-VS), during the Covid-19 pandemic. This is an experience report carried out in the municipality of Sobral, from March to October 2020, which included: the qualification of work management and health education activities, through selective processes and training of professionals to work with Covid-19 prevention and treatment. It became evident that the definition of profiles consistent with management and health care strategies was essential, furthering the realization of selective processes for professional categories working at different levels of care. The qualification of the workers encompassed several professional categories and different training levels, promoting an interprofessional and collaborative practice. We underscore the relevance of this experience, especially in situations related to facing urgent public health issues, and consider it a trigger to reflect on new ways to work with health and (re)invent themselves in different situations.

\section{RESUMEN}

Este manuscrito tiene como objetivo describir la experiencia de educación, en el ámbito de la salud, desarrollada por la Secretaria de Salud de Sobral, por medio de la Escuela de Salud Pública Visconde de Saboia (ESP-VS), durante la pandemia de Covid-19. Se trata de un relato de experiencia realizada en el municipio de Sobral, de marzo hasta octubre de 2020, en la que se contempló: la calificación de las actividades de gestión del trabajo y de la educación en la salud, por medio de procesos selectivos y formación de profesionales para actuar en la prevención y tratamiento de la Covid-19. Se evidenció que era fundamental la definición de perfiles coherentes con las estrategias de gestión y cuidado en salud, fomentando la realización de procesos selectivos para categorías profesionales que actúan en diferentes niveles de la atención. La calificación de los trabajadores abarcó diversas categorías profesionales y diferentes niveles de formación, promoviendo una práctica interprofesional y colaborativa. Se señala la relevancia de esta experiencia, sobre todo en situaciones relacionadas al enfrentamiento de problemas de salud pública en carácter de urgencia, considerándolo un disparador de reflexiones sobre las nuevas formas de hacer salud y (re) inventarse en situaciones diversas.

\section{INTRODUÇÃO}

Ao longo dos 30 anos de criação do Sistema Único de Saúde (SUS) e das consequentes mudanças nos modos de produção da atenção à saúde no Brasil, ampliou-se a necessidade de reorientação das práticas por parte dos trabalhadores do SUS, sendo este um dos desafios que necessitam ser enfrentados pelos gestores do sistema de saúde e instituições formadoras. Intenta-se refletir sobre o cuidado, até então orientado por uma perspectiva eminentemente curativa e hospitalocêntrica, fomentando a ressignificação dos processos de trabalho de forma que assumam novos sentidos e impulsionem os trabalhadores a vivenciar uma nova prática ${ }^{1}$.

Para corresponder a esse desafio, o Ministério da Saúde (MS) criou, em 2003, a Secretaria de Gestão do Trabalho e da Educação na Saúde (SGTES), assumindo o papel já definido na legislação, ou seja, de gestor federal do SUS na formulação das políticas orientadoras da formação, desenvolvimento, distribuição, regulação e gestão dos trabalhadores de saúde no Brasil. Com uma pauta diversificada e comprometida com a qualidade, na qual novos desafios se somam a antigos, a gestão do trabalho e da educação na saúde vem reforçando sua posição como prioritária para resolver grande parte dos problemas do SUS².

Ao longo de sua existência, a SGTES adotou inúmeras estratégias indutoras com investimentos técnicos, políticos e financeiros para a qualificação da gestão, produzindo impactos significativos no processo de condução das políticas públicas de saúde ${ }^{3}$. Tais decisões políticas e administrativas possibilitam o estabelecimento de iniciativas relacionadas à gestão do trabalho na saúde, à reorientação da formação profissional e à educação permanente dos trabalhadores da saúde. Contabilizam-se muitos avanços, contudo há desafios a serem superados e propostas a serem implementadas e/ou readequadas que colaborem para a melhoria da capacidade resolutiva dos sistemas nacionais de saúde ${ }^{4}$.

0 ano de 2020, que deixa marcas severas na saúde pública em todo o mundo, aponta novas exigências 
de caráter epidemiológico, no cenário brasileiro, como reflexos da pandemia causada pelo novo coronavírus (Covid-19), tais como a implementação de novas estratégias no campo do binômio educação e trabalho.

0 município de Sobral, localizado na zona Norte do estado do Ceará, vem empreendendo esforços em seu sistema saúde escola, por meio de um plano de contingências, para ampliar a capacidade de enfrentamento da Covid-19 e fortalecer iniciativas de gestão e educação, no âmbito da saúde, em consonância com as realidades mundial, nacional e local.

Dentre as medidas adotadas pelo gestor municipal, destacam-se: a intervenção no Hospital Dr. Estevam Ponte, até então administrado por uma organização social, passando, agora, a ser gerido pela Secretaria Municipal da Saúde (SMS); a criação do Hospital de Campanha Dr. Alves; o reordenamento de serviços como Unidades Básicas de Saúde (UBS); a criação do plantão epidemiológico; a implantação de estratégias de monitoramento de indicadores e do Escritório de Crise para monitorar e analisar dados, bem como (re) definir as estratégias de intervenção adotadas. Essa ampliação da estrutura e da oferta de serviços pelo município demandou urgente contratação temporária e treinamento de profissionais especializados.

É nesse contexto que se considera essencial a divulgação das experiências exitosas e inovadoras, de modo a produzir evidências que subsidiem a tomada de decisão das demais esferas de gestão e apontar limites e possibilidades que se apresentem no campo da gestão do trabalho e da educação na saúde em função das intensas mudanças ocorridas no ano em curso (2020).

Parte-se do pressuposto que a qualificação das atividades de gestão do trabalho e da educação na saúde, o debate e a publicização das principais ações implementadas ou em curso subsidiarão o planejamento, a reorientação e a continuidade das políticas e programas de saúde e, consequentemente, a expansão do acesso e da melhoria da qualidade dos serviços prestados à população $0^{4}$.

Busca-se, portanto, contribuir nos campos teórico e prático da educação e trabalho na saúde, com foco na seleção e desenvolvimento dos trabalhadores, por meio da divulgação de ações que alcançaram resultados relevantes, com vistas à sustentabilidade das mesmas. 0 presente manuscrito objetiva descrever a experiência de ações que integram os campos da educação e do trabalho em saúde desenvolvidas pelo

\section{"Fortalecer iniciativas de gestão e educação, no âmbito da saúde, em consonância com as realidades mundial, nacional e local"}

Sistema Municipal de Saúde de Sobral durante a pandemia de Covid-19.

Este manuscrito se apresenta como oportunidade para sistematizar evidências, a partir dos autores envolvidos, além de tornar públicos os esforços empreendidos por trabalhadores, gestores e pesquisadores neste período pandêmico.

\section{METODOLOGIA}

Este estudo caracteriza-se como relato de experiência e foi desenvolvido no município de Sobral pela Secretaria Municipal da Saúde, por meio da Escola de Saúde Pública Visconde de Saboia (ESPVS), no período de março a outubro de 2020. Sobral situa-se na região norte do território cearense e é referência para o atendimento de alta complexidade em saúde para 55 municípios da região. Desde a confirmação do primeiro caso de Covid-19 em sua abrangência, em 18/03/2020, até o dia 09/12/2020, Sobral apresentou 12.344 diagnósticos confirmados da doença, em um cenário de 321 óbitos e 12.178 pacientes recuperados ${ }^{5}$.

Diante do contexto pandêmico anunciado pela Organização Mundial da Saúde (OMS), o município elaborou um plano de contingência e adotou uma série de medidas tanto para evitar a propagação da doença quanto para assegurar o atendimento necessário às pessoas por ela afetadas. Tais medidas contemplaram desde a reorganização de estruturas e fluxos de atendimento até a seleção emergencial e formação de profissionais para atuar na prevenção e tratamento da Covid-19, dentre outras.

A experiência ora relatada contemplou atividades com profissionais que atuam no sistema municipal de saúde local, as quais, em consonância com os preceitos éticos, serão aqui apresentadas sem qualquer utilização de informações que identifiquem ou possibilitem prejuízo aos sujeitos.

Um elemento fundamental nesse contexto remete às possibilidades financeiras da Secretaria da Saúde 
de Sobral para a adoção de estratégias em caráter emergencial, objeto de sistematização e análise do terceiro artigo publicado neste Dossiê Temático. Diante da excepcionalidade do momento e da especificidade das receitas e despesas pertinentes, o orçamento anual da SMS necessitou de ajustes para assegurar a correta execução financeira. Foram necessárias portarias e normas técnicas que fundamentassem e resguardassem as alterações orçamentárias que se assinalavam e deveriam ocorrer em curto período de tempo. De modo célere, foram alinhadas as novas receitas e despesas ao orçamento e aos instrumentos de gestão, bem como foram intensificadas as compras de insumos e equipamentos necessários.

Emergiu a necessidade tanto da garantia de materiais quanto da ampliação do quadro de profissionais para atuar na prevenção ao novo coronavírus e no tratamento de pessoas acometidas por Covid-19. Além do afastamento de profissionais em virtude de adoecimentos, o aumento do fluxo em alguns equipamentos (tanto nos que já existiam quanto nos que foram criados emergencialmente) alterou a dinâmica dos serviços, resultando no remanejamento de trabalhadores e na lacuna quantitativa e qualitativa de profissionais. Verificou-se também a necessária ampliação do número de trabalhadores e que estes precisavam de qualificação para atuar no contexto pandêmico de uma doença ainda pouco conhecida pela ciência.

Para a contração em tempo hábil, normativas do município, em consonância com as regras federais e estaduais, redundaram na decretação de Estado de Emergência no âmbito do Município de Sobral, estabelecido no Decreto Municipal n. ${ }^{0} 2.371^{6}$, de 16 de março de 2020, bem como na criação de vagas temporárias estabelecidas nos Decretos Municipais n. ${ }^{\circ} 2.367^{7}$, de 13 de março de 2020 e n. ${ }^{\circ} 2.387^{8}$, de 29 de março de 2020, que permitiram a contratação imediata de profissionais voltados ao combate da pandemia ${ }^{6}$.

A realização de processos seletivos em caráter de urgência foi inevitável, de modo que a operacionalização destes ficou sob a responsabilidade da ESP-VS, instituição pública vinculada à Secretaria Municipal da Saúde de Sobral, que imediatamente procedeu ao planejamento necessário à seleção de profissionais nesse contexto. Ao contrário de experiências anteriores, optou-se pela utilização dos meios virtuais em todo o processo, considerando-se as orientações sanitárias e a condição de teletrabalho

\section{"Ampliação do quadro de profissionais para atuar na prevenção ao novo coronavírus e no tratamento de pessoas acometidas por Covid-19"}

na qual se encontrava a equipe da ESP-VS.

A eminência de atendimento e prevenção a uma doença ainda pouco conhecida pela ciência trouxe a necessidade de qualificação dos profissionais para que fosse possivel maior segurança e assertividade nos cuidados relacionados à Covid-19. Esse contexto foi o pressuposto para a organização de processos formativos, realizados nos modos presencial e virtual, voltados aos trabalhadores que atuam no sistema municipal de saúde de Sobral e aos estudantes que continuavam em práticas do internato nesse período pandêmico.

A formação realizada presencialmente, por meio do curso de Higienização e Limpeza, contemplou profissionais que atuam na limpeza de ambientes hospitalares e têm restrições quanto ao uso de tecnologias digitais.

Quanto à oferta de formação não presencial, a ESPVS utilizou seu Ambiente Virtual de Aprendizagem (AVA), denominado Plataforma Saboia, para realizar cursos de curta duração e capacitar os profissionais que já atuavam no sistema local de saúde, bem como os recém-contratados e estudantes que cumpriam internato dos cursos de Enfermagem e de Medicina das instituições de Ensino Superior de Sobral.

0 s cursos buscavam contemplar variadas categorias profissionais, sendo organizadas turmas com enfoques temáticos específicos quanto à prevenção e tratamento do novo coronavírus. A carga horária de 40 horas foi distribuída em quatro módulos, com duração média de 20 dias, a fim de preparar os profissionais para conhecer as características gerais da doença, as medidas de prevenção e controle, os fluxos para o atendimento do paciente e a realização de seu manejo clínico, resguardadas as especificidades das categorias.

0 presente estudo não necessitou de apreciação pelo Comitê de Ética em Pesquisa (CEP) por se tratar de pesquisa que utiliza informações de domínio público, sem identificação individual de participantes e com 
o intuito exclusivo de relatar a experiência das atividades de seleção e de formação desenvolvidas na prática profissional, conforme Resolução 510/2016 do Conselho Nacional de Saúde/Ministério da Saúde9.

\section{RESULTADOS E DISCUSSÃO}

Esta seção apresenta os resultados e pretende estimular reflexões sobre a experiência de gestão e desenvolvimento de pessoas (trabalhadores), que transitou no campo da gestão do trabalho, mas evidencia sua centralidade na educação na saúde. Assim, serão apresentados resultados nestes dois campos, similares em seu propósito e complementares na perspectiva teórico-prática.

\section{Seleção de trabalhadores: identificando potências para o SUS em Sobral}

A demanda por profissionais com perfis coerentes com as estratégias de gestão e de cuidado no SUS foi apresentada à ESP-VS pela gestão da SMS, fomentando a realização de processos seletivos para categorias profissionais que atuam em diferentes níveis da atenção à saúde. A definição destes perfis foi fundamental e tomou como parâmetro os conhecimentos relacionados à Covid-19 compartilhados pela 0MS e a realidade local frente à pandemia, inclusive quanto aos serviços de saúde que foram criados e/ou reestruturados.

0 período pandêmico requereu e possibilitou a flexibilização nas normativas e regras que orientam a realização de processos seletivos e a contratação de pessoas mediante financiamento oriundo dos recursos públicos. A publicação de decreto municipal autorizando a contratação de profissionais por tempo determinado para atender às demandas temporárias trazidas pela pandemia espelhou o compromisso com a celeridade de medidas que se mostravam necessárias.

Por conseguinte, foram realizados diversos processos seletivos, conforme elencados no Quadro 1, explicitando o expressivo número de 1.743 inscritos.

Quadro 1 - Processos seletivos realizados com vistas à contratação de profissionais para o enfrentamento da Covid-19.

\begin{tabular}{|c|c|c|c|}
\hline EDITAL & DESCRIÇÃ 0 & FUNÇÕES & $\begin{array}{c}N^{\circ} \mathrm{DE} \\
\text { INSCRITOS }\end{array}$ \\
\hline $01 / 2020$ & $\begin{array}{l}\text { Processo seletivo simplificado para } \\
\text { formação de cadastro de reserva } \\
\text { destinado à contratação temporária } \\
\text { de excepcional interesse público de } \\
\text { profissionais para o enfrentamento do } \\
\text { novo coronavírus causador da Covid-19, } \\
\text { conforme decretos municipais n. } 2.367 \text {, } \\
\text { de } 13 \text { de março de } 2020 \text { e n. } 2.387 \text {, de } 29 \\
\text { de março de } 2020 .\end{array}$ & $\begin{array}{c}\text { Auxiliar de Escritório } \\
\text { Recepcionista } \\
\text { Almoxarife } \\
\text { Encarregado de Manutenção } \\
\text { Maqueiro } \\
\text { Auxiliar de Farmácia } \\
\text { Técnico de Enfermagem (40h e } \\
\text { plantonista) } \\
\text { Técnico de Radiologia } \\
\text { Assistente Social } \\
\text { Enfermeiro (40h e plantonista) } \\
\text { Fisioterapeuta (40h e } \\
\text { plantonista) } \\
\text { Farmacêutico (36h e } 40 \mathrm{~h} \text { ) } \\
\text { Médico (07 especialidades) } \\
\text { Nutricionista }\end{array}$ & 1.372 \\
\hline
\end{tabular}




\begin{tabular}{|c|c|c|c|}
\hline EDITAL & DESCRIÇÃO & FUNÇÕES & $\begin{array}{c}\mathrm{N}^{\circ} \mathrm{DE} \\
\text { INSCRITOS }\end{array}$ \\
\hline $04 / 2020$ & $\begin{array}{c}\text { Processo seletivo simplificado para } \\
\text { formação de cadastro de reserva } \\
\text { destinado à contratação temporária } \\
\text { de excepcional interesse público de } \\
\text { profissionais plantonistas conforme } \\
\text { decreto municipal n } .^{\circ} 2.387 \text {, de } 29 \text { de } \\
\text { março de } 2020 \text {. }\end{array}$ & $\begin{array}{l}\text { Assistente Social } \\
\text { Enfermeiro } \\
\text { Médico }\end{array}$ & 63 \\
\hline $05 / 2020$ & $\begin{array}{l}\text { Processo seletivo simplificado para } \\
\text { formação de cadastro de reserva } \\
\text { destinado à contratação temporária } \\
\text { de excepcional interesse público de } \\
\text { profissionais destinados ao sistema } \\
\text { municipal de saúde de Sobral e } \\
\text { destinados ao enfrentamento do novo } \\
\text { coronavírus causador da Covid-19, } \\
\text { conforme decretos municipais n. } .^{\circ} 2.367 \text {, } \\
\text { de } 13 \text { de março de } 2020 \text { e n. } .^{\circ} 2.426 \text {, de } 09 \\
\text { de maio de } 2020 .\end{array}$ & $\begin{array}{c}\text { Técnico de Enfermagem } \\
\text { Médico }\end{array}$ & 44 \\
\hline $10 / 2020$ & $\begin{array}{l}\text { Processo seletivo simplificado para } \\
\text { formação de cadastro de reserva } \\
\text { destinado à contratação temporária } \\
\text { de excepcional interesse público de } \\
\text { profissionais destinados ao sistema } \\
\text { municipal de saúde de Sobral e } \\
\text { destinados ao enfrentamento do novo } \\
\text { coronavírus causador da Covid-19, } \\
\text { conforme decreto municipal n. } .^{\circ} 2.426 \text {, de } \\
09 \text { de maio de } 2020 .\end{array}$ & $\begin{array}{c}\text { Auxiliar de Farmácia } \\
\text { Maqueiro } \\
\text { Técnico de Enfermagem }\end{array}$ & 264 \\
\hline \multicolumn{3}{|l|}{ TOTAL } & 1.743 \\
\hline
\end{tabular}

Fonte: Elaborado pelos autores.

Com o intuito de oportunizar a participação do maior número de candidatos, bem como otimizar o fluxo administrativo, a SMS optou pela isenção de taxa de inscrição nos processos seletivos. 0s editais ofertavam vagas para diversas categorias, contemplando graduados e não graduados.

Destaca-se o primeiro desses processos, regido pelo edital 01/2020, considerando-se os 1.372 candidatos para o certame. Destes, 879 eram candidatos de nível médio e 493 eram graduados. 0 edital inaugural ofertou vagas para 24 categorias, sendo nove categorias de nível médio e 15 categorias de graduados. 0bservou-se que, além daqueles que residem em Sobral, participaram candidatos de 40 outros municípios cearenses, além de pessoas de outros dois estados brasileiros. 0 processo seletivo teve a duração de 18 dias, contemplando análise curricular dos interessados, conforme critérios elencados em consonância com os perfis que se apontavam como necessários.

A opção pela modalidade virtual para a realização do processo seletivo trouxe ganhos e limitações. Destas, destaca-se a dificuldade de acesso e uso das tecnologias digitais por parte de algumas pessoas. Ao analisar o acesso à educação por meios digitais durante a pandemia de Covid-19, observa-se que no Brasil não havia preparação para enfrentar essa realidade, mas que fatores tangenciais, como questões socioeconômicas, tendem a dificultar ou mesmo inviabilizar esse acess $0^{10}$. 
Quanto aos ganhos advindos, é oportuno ressaltar a redução do impacto ambiental e de custos, a partir da economia no uso de papel. Além desses, a possibilidade de participação de pessoas de vários municípios mostra um ganho na perspectiva da ampliação do raio de alcance do processo seletivo.

Importa refletir, porém, que o aumento no quantitativo de candidatos não necessariamente espelha a adequação do perfil profissional necessário para a atuação frente à Covid-19. Nesse sentido, a experiência evidenciou uma lacuna importante no que tange ao número de profissionais que buscam oportunidade de trabalho, mas não apresentam atuação ou formação em urgência e emergência. A expectativa quanto a esses elementos decorreu das demandas que emergiram relacionadas a condutas e procedimentos específicos em atendimentos à Covid-19.

Outro aspecto observado se correlaciona à capacidade de atuação interprofissional, haja vista que foram requeridos trabalhadores de diversas funções, dentre graduados e não graduados. Ao refletir sobre a interprofissionalidade, importa considerar que os desafios do trabalho no SUS remetem à necessidade de práticas integradas e colaborativas para atender aos novos desafios colocados aos modelos de atenção, que devem ser orientados para a integralidade da saúde dos indivíduos ${ }^{11}$. A efetivação de atividades colaborativas e integradas para 0 enfrentamento da Covid-19 apresentou-se como uma intencionalidade em todos os serviços de saúde.

A seleção de profissionais, neste atípico período, tensionou o desenvolvimento de novos modus operandi para a identificação de trabalhadores que mais se aproximassem dos perfis necessários. Somou-se, ainda, a necessidade de qualificação desses trabalhadores que ingressaram nos serviços de saúde, com o intuito de contribuir para a melhoria da assistência prestada.

\section{Elos teóricos e práticos da Educação na Saúde durante a pandemia de Covid-19}

Ancorada no referencial teórico e metodológico da Educação Permanente em Saúde (EPS), a Secretaria Municipal da Saúde de Sobral, por meio da ESP-VS, planejou, implementou e avaliou processos formativos para os trabalhadores da saúde atuantes no enfrentamento da Covid-19 em âmbito local. Foi possível abranger trabalhadores de diversas categorias profissionais e diferentes

\section{"A seleção de profissionais, neste atípico periodo, tensionou o desenvolvimento de novos modus operandi para a dentificação de trabalhadores"}

níveis de formação, bem como fomentar uma prática interprofissional e colaborativa.

$\mathrm{Na}$ perspectiva da EPS, toda intervenção emana da análise problematizadora dos contextos reais da prática, no entendimento de que no trabalho também se aprende e se produz conhecimentos que abrem caminhos para a experimentação de novas ações de enfrentamento aos problemas ${ }^{4}$. A ESP-VS tomou em consideração essa concepção político-pedagógica, instituída formalmente por meio da Política Nacional de Educação Permanente em Saúde (PNEPS).

A PNEPS, que representa um marco para a área da educação na saúde, é resultado de muitas lutas e esforços promovidos pelos defensores do tema, que a compreendem como estratégia imprescindivel para a modificação das práticas de saúde e, portanto, para a melhoria da qualidade da atenção à saúde ${ }^{12}$.

As ações desenvolvidas no campo da educação na saúde, envolvendo a formação em abordagem e manejo clínico de pessoas com Covid-19, resultaram em contribuições importantes nos campos teórico e prático para o sistema saúde escola de Sobral. Com isso, evidenciaram-se algumas contribuições relacionadas à gestão, atenção e formação em saúde por meio desses processos formativos: a qualificação do trabalho em saúde durante o enfrentamento à pandemia, a melhoria na qualidade da assistência à população, o estímulo às práticas colaborativas e o fortalecimento da integração ensino-serviçocomunidade.

A realização do curso de Higienização e Limpeza consistiu em um desafio por contemplar aspectos teóricos e práticos, dentro do ambiente hospitalar, num período de grande incidência de Covid-19. 0 curso foi solicitado pela gestão do serviço para orientar e alinhar práticas na higienização do hospital. Sua estruturação e a elaboração do material requisitaram elementos orientadores para a atuação na pandemia, embora até então existissem poucos estudos validados sobre a temática. Outro desafio foi programar um cronograma que contemplasse 
todos os trabalhadores em suas diversas escalas. Ainda assim, foi possivel contemplar todos os trabalhadores do hospital, resguardando as orientações sanitárias pertinentes.

É mister destacar, porém, um elemento importante nessa formação: a inserção das Tecnologias Digitais da Informação e Comunicação (TDIC) nos processos de educação em saúde, em especial dos Ambientes Virtuais de Aprendizagem. Verificou-se uma melhoria na aquisição e no desenvolvimento de habilidades com as chamadas "novas tecnologias", as quais agregam um leque de possibilidades quanto ao atendimento qualificado da população, utilizando os meios virtuais para monitoramento e controle de doenças, em especial a Covid-19, como os serviços do Telessaúde (ofertados pelo Ministério da Saúde), com teleconsultoria, telediagnóstico e segunda opinião formativa; preenchimento adequado de sistemas de informação com dados epidemiológicos, dentre outros.

As TDIC se apresentam como ferramentas efetivas no enfrentamento mundial à disseminação da Covid-19, seja no monitoramento, divulgação de informações de prevenção e contágio ou no suporte à análise de indicadores epidemiológicos. Esse cenário, por sua vez, suscitou aos trabalhadores da saúde a aquisição das habilidades no manuseio das tecnologias digitais ${ }^{13}$.

A adoção de metodologias de compartilhamento de conteúdos por meio da Plataforma Saboia fomentou o uso dessas tecnologias e resultou no desenvolvimento de 29 turmas em processos formativos direcionados a diferentes públicos, conforme descrito no Quadro 2.

Quadro 2 - Cursos desenvolvidos pela ESP-VS durante a pandemia de Covid-19. Sobral, Ceará, 2020.

\begin{tabular}{|l|c|c|}
\hline Curso & Público-alvo & $N^{0}$ Turmas \\
\hline Abordagem e manejo clínico às pessoas com Covid-19 & Médicos & 4 \\
Abordagem e manejo clínico às pessoas com Covid-19 & Enfermeiros & 5 \\
Abordagem e manejo clínico às pessoas com Covid-19 & Técnicos de Enfermagem & 3 \\
Abordagem e manejo clínico às pessoas com Covid-19 & $\begin{array}{c}\text { Estudantes - Internos de } \\
\text { Enfermagem }\end{array}$ & 4 \\
Abordagem e manejo clínico às pessoas com Covid-19 & Estudantes - Internos de & 4 \\
Prevenção ao novo coronavírus e abordagem às pessoas com & Agentes Comunitários de \\
Covid-19 Saúde & 6 \\
Odontologia na Prevenção e Abordagem à Covid-19 & Cirurgiões Dentistas, \\
Covid-19: uma abordagem interprofissional & $\begin{array}{c}\text { Técnicos em Saúde Bucal e } \\
\text { T0TAL }\end{array}$ & 1 \\
\hline
\end{tabular}

Fonte: Elaborado pelos autores.

Com sua realização na modalidade de Educação a Distância (EaD), os cursos contaram com 846 inscritos. $A$ EaD vem corresponder à necessidade de recursos tecnológicos que possibilitem programas educativos mais interativos. Uma característica importante dessa modalidade de ensino é a flexibilidade no que tange aos horários de estudo e de participação nas atividades ${ }^{14}$. Conforme relato dos participantes, na experiência vivenciada, o acesso assíncrono às ferramentas e recursos disponíveis nos Ambientes Virtuais de Aprendizagem possibilitou aos profissionais autonomia e interação.

A utilização da ferramenta fórum de discussão, no AVA, em todos os módulos dos cursos, fomentou a prática colaborativa entre os profissionais na construção do conhecimento. Esse tipo de interação entre os participantes permite a construção de um novo pensamento coletivo, bem como oportuniza a cada trabalhador reconhecer-se quanto ao conhecimento adquirido sobre as temáticas abordadas ${ }^{15}$.

A relevância destes conhecimentos sobressaiu para todos os trabalhadores da área da saúde, ainda que não estivessem atuando diretamente no tratamento de pessoas infectadas, a exemplo dos Agentes Comunitários de Saúde (ACS). Não obstante, a realização do curso específico para os ACS considerou a necessária reorganização do processo de trabalho, com foco no monitoramento de casos e na orientação para a prevenção da Covid-19, sobretudo quanto aos aspectos socioculturais que permeiam a realidade nos territórios da Estratégia Saúde da 
Família e que podem contribuir para o adoecimento das pessoas.

A necessidade de participação dos profissionais das diversas categorias no cenário pandêmico suscitou o desenvolvimento de duas turmas do curso "Covid-19: uma abordagem interprofissional", voltadas para os residentes de diferentes categorias inseridos nos Programas de Residências Multiprofissionais em Saúde da Família e em Saúde Mental executadas pela ESP-VS. Esse curso favoreceu a construção do conhecimento pautada nas premissas de cada categoria profissional, propiciando a realização de importantes diálogos relacionados às medidas de biossegurança na prevenção e controle da Covid-19 e à saúde do trabalhador.

Já a oferta do curso "Abordagem e manejo clínico às pessoas com Covid-19" para estudantes que cumpriam internato dos cursos de Enfermagem e Medicina, além de contribuir para uma formação humanista, integral, crítico-reflexiva e alinhada à realidade atual, favoreceu o fortalecimento da integração ensino-serviço-comunidade. Esta integração consiste no trabalho conjunto de acadêmicos, professores, gestores e profissionais que compõem as instituições de saúde, visando melhorar a atenção individual e coletiva e reorientar o processo educativo e a formação profissional na área da saúde ${ }^{16}$.

A literatura aponta que esforços conjuntos entre os serviços e as universidades são necessários para aumentar a contratação de profissionais para equipes de apoio, instituir protocolos de ação para diferentes cenários sociais, garantir os insumos necessários para aumentar o atendimento e garantir formação a todos os profissionais em consonância com as realidades local, nacional e mundial ${ }^{17}$.

Por meio dessas estratégias, anseia-se que as oportunidades educativas se multipliquem e se transformem em processos permanentes de participação intersetorial e interprofissional e que sejam capazes de dar conta da complexidade dos nossos territórios, em que se reconhece que 0 trabalho em saúde é capaz de criar e recriar outros modos de fazer, cuidar, atender e assistir, além de promover formação e qualificação ${ }^{4}$.

\section{CONCLUSÃO}

As evidências deste relato apontam a relevância da integração entre a gestão do trabalho e a educação na saúde, iniciando-se no processo de

\section{"A aproximação entre \\ a seleção e a formação \\ em saúde possibilita \\ ambientes cooperativos, \\ dialógicos, coordenados e \\ que valorizam as diversas \\ formas de cuidado no SUS"}

seleção de trabalhadores, a partir de perfis prédefinidos, perpassando pelo desenvolvimento destes, em situações relacionadas ao enfrentamento de problemas de saúde pública em caráter de urgência. Reconhece-se que a identificação de perfis profissionais nem sempre corresponde às demandas apontadas, seja por gestores, seja pelos contextos em si. Por vezes, as incompletudes são heranças de processos formativos fragilizados, permeados por fatores que transcendem as estruturas dos cursos.

Todavia, a imperativa necessidade de assegurar profissionais de saúde com os conhecimentos mínimos para o enfrentamento da Covid-19 fomentou o desenvolvimento de ações formativas, as quais possibilitaram a sistematização de conteúdos, a intensificação do uso das tecnologias em processos de educação em saúde e o diálogo virtual de profissionais, fundamental para a ressignificação das práticas, sejam individuais ou coletivas.

Reafirma-se, portanto, que a aproximação entre a seleção e a formação em saúde possibilita ambientes cooperativos, dialógicos, coordenados e que valorizam as diversas formas de cuidado no SUS.

Compreende-se que a experiência ora relatada colaborou para a qualificação da atenção à saúde por meio da seleção assertiva de perfis profissionais e desenvolvimento de processos formativos diversos, os quais, por meio das tecnologias digitais, pautaram-se no trabalho colaborativo, responsável e efetivo. Outra contribuição se deu no âmbito teórico, com o enriquecimento da literatura sobre o tema, compreendendo o relato de vivências como uma tipologia de pesquisa que aproxima os leitores às realidades vivenciadas no município, no Brasil e no mundo.

Nesse tocante, ao considerar este relato um disparador de reflexões sobre as novas formas de se fazer saúde e se (re)inventar em situações de emergência pública, sugere-se a realização de outros estudos sobre a temática, de modo que estes 
possam desenvolver uma análise de impacto dessas estratégias vivenciadas em âmbito local.

\section{CONTRIBUIÇÃO DOS AUTORES}

Marcia Maria Santos da Silva contribuiu com redação, análise e revisão crítica do manuscrito. Karina Oliveira de Mesquita contribuiu com redação, análise e revisão crítica do manuscrito. Fabricia Rocha de Meneses Farias contribuiu com redação, análise e revisão crítica do manuscrito. Francisco Elder Escossio Barros contribuiu com redação, análise e revisão crítica do manuscrito. José Clauber Matos Brayner contribuiu com redação, análise e revisão crítica do manuscrito. Maria José Galdino Saraiva contribuiu com redação, análise e revisão crítica do manuscrito.

\section{REFERÊNCIAS}

1. Silva MMS. Efetividade da Residência Multiprofissional em Saúde da Família: uma análise a partir do quadrilátero da formação para a área da saúde [dissertação]. Fortaleza (CE): Universidade Estadual do Ceará; 2014.

2. Lima RRT. Formação em gestão do trabalho e da educação na saúde: relatando uma experiência educativa. Saúde Debate [serial on the internet]. 2020 [cited 2020 Nov 30];44(126):919-29. Available from: https://www.scielo.br/pdf/sdeb/ v44n126/0103-1104-sdeb-44-126-0919.pdf

3. Magnago C, Pierantoni CR, França $T$, Vieira SP, Miranda RG, Nascimento ND. Política de Gestão do Trabalho e Educação em Saúde: a experiência do ProgeSUS. Cienc Saúde Colet [serial on the internet]. 2017 [cited 2020 Nov 30];22(5):1521-30. Available from: http://dx.doi.org/10.1590/1413$\underline{81232017225.32962016}$

4. França T, Magnago C. Políticas, programas e ações de educação na saúde: perspectivas e desafios. Saúde Debate [serial on the internet]. 2019 [cited 2020 Nov 30];43(spe1):4-7. Available from: https:// www.scielo.br/pdf/sdeb/v43nspe1/0103-1104sdeb-43-spe01-0004.pdf

5. Sobral. Boletim epidemiológico Covid-19 [document on the internet]. Sobral: Secretaria da Saúde; 2020 [cited 2020 Dec 10]. Available from: $\quad$ http://www.sobral.ce.gov.br/ informes/principais/boletim-covid-19-emsobral

6. Sobral. Decreto n. ${ }^{0}$ 2.371, de 16 de março de 2020. Decreta estado de emergência no âmbito do Município de Sobral e estabeleceu medidas para enfrentamento do novo coronavírus (COVID-19) [document on the internet]. Diário Oficial do
Município, Sobral (2020 Mar 16 [cited 2020 Dec 12]). Available from: http://www.sobral.ce.gov.br/ diario/public/files/diario/9bf7ba4ae2931bdf14 b3a48b5240d141.pdf

7. Sobral. Decreto n. ${ }^{0} 2.367$, de 13 de março de 2020. Autoriza a secretaria municipal da saúde a realizar contratação de profissionais por tempo determinado para atender a necessidade temporária de excepcional interesse público. Diário Oficial do Município, Sobral (2020 Mar 13 [cited 2020 Dec 12]). Available from: http://www.sobral. ce.gov.br/diario/public/files/diario/00eb e56060c94df734b04637524ca2eb.pdf

8. Sobral. Decreto n. ${ }^{\circ} 2.387$, de 29 de março de 2020. Autoriza a secretaria municipal da saúde a realizar contratação de profissionais por tempo determinado para atender a necessidade temporária de excepcional interesse público. Diário Oficial do Município, Sobral (2020 Mar 13 [cited 2020 Dec 12]). Available from: http://transparencia.sobral. ce.gov.br/arquivo/nome:5b00b1c7ef1c0ca11 d1ce1f5d35eb408.pdf

9. Brasil. Resolução n. ${ }^{\circ}$ 510, de 01 de abril de 2016. Dispõe sobre as normas aplicáveis a pesquisa em ciências humanas e sociais. Diário Oficial da União, Sobral (2016 Apr 01 [cited 2020 Dec 18]). Available from: https://bvsms.saude.gov.br/bvs/ saudelegis/cns/2016/res0510 $0704 \quad 2016 . \mathrm{html}$

10. Cardoso CA, Ferreira VA, Barbosa, FCG. (Des) igualdade de acesso à educação em tempos de pandemia: uma análise do acesso às tecnologias e das alternativas de ensino remoto. Rev Com Censo [serial on the internet]. 2020 [cited 2020 Dec 18];7(3). Available from: http://www.periodicos.se.df.gov. br/index.php/comcenso/article/view/929/554

11. Peduzzi M. Educação interprofissional para o desenvolvimento de competências colaborativas em saúde. In: Toassi RFC, organizador. Interprofissionalidade e formação na saúde: onde estamos? Porto Alegre: Rede UNIDA; 2017. p. 40-48.

12. Brasil. Política Nacional de Educação Permanente em Saúde: o que se tem produzido para o seu fortalecimento? Brasília (DF): Ministério da Saúde; 2018.

13. Organização Mundial da Saúde, Organização Pan-Americana da Saúde. A Covid-10 e o papel dos Sistemas de Informação e das Tecnologias na Atenção Primária [document on the internet]. 2020 [cited 2020 Dec 18];7. Available from: https://iris. paho.org/bitstream/handle/10665.2/52206/ COVID19FactsheetPNA por.pdf? sequence $=15$

14. Silva NA, Santos AMG, Cortez EA, Cordeiro BC. Limites e possibilidades do ensino à distância (EaD) na educação permanente em saúde: revisão integrativa. Cien Saúde Colet [serial on the internet]. 2015 [cited 2020 Dec 18]; 20(4):10991107. Available from: https://www.scielosp.org/ $\mathrm{pdf} / \mathrm{csc} / 2015 . v 20 \mathrm{n} 4 / 1099-1107 / \mathrm{pt}$ 
15. Werneck A, Frutuoso I, Doimo T, Marqui R, Contrin L, Mendonça-Ribeiro R. Desenvolvimento e Implantação de um Ambiente Virtual de Aprendizagem para Educação Continuada em Terapia Intensiva. Rev Enferm UFPE on line [serial on the internet]. 2019 [cited 2020 Dec 18];13(5). Available from: https://periodicos. ufpe.br/revistas/revistaenfermagem/ article/view/238907

16. Luz AL. Atenção primária como cenário de prática de uma escola médica no Brasil: avaliação da integração ensino serviço [dissertação]. São Luís (MA): Universidade Federal do Maranhão; 2019.

17. Pinho SB. A Atenção Primária a Saúde no contexto da COVID19. HU Revista [serial on the internet]. 2020 [cited 2020 Dec 18];46:12. Available from: https://periodicos.ufjf.br/ index.php/hurevista/article/view/30077/20361
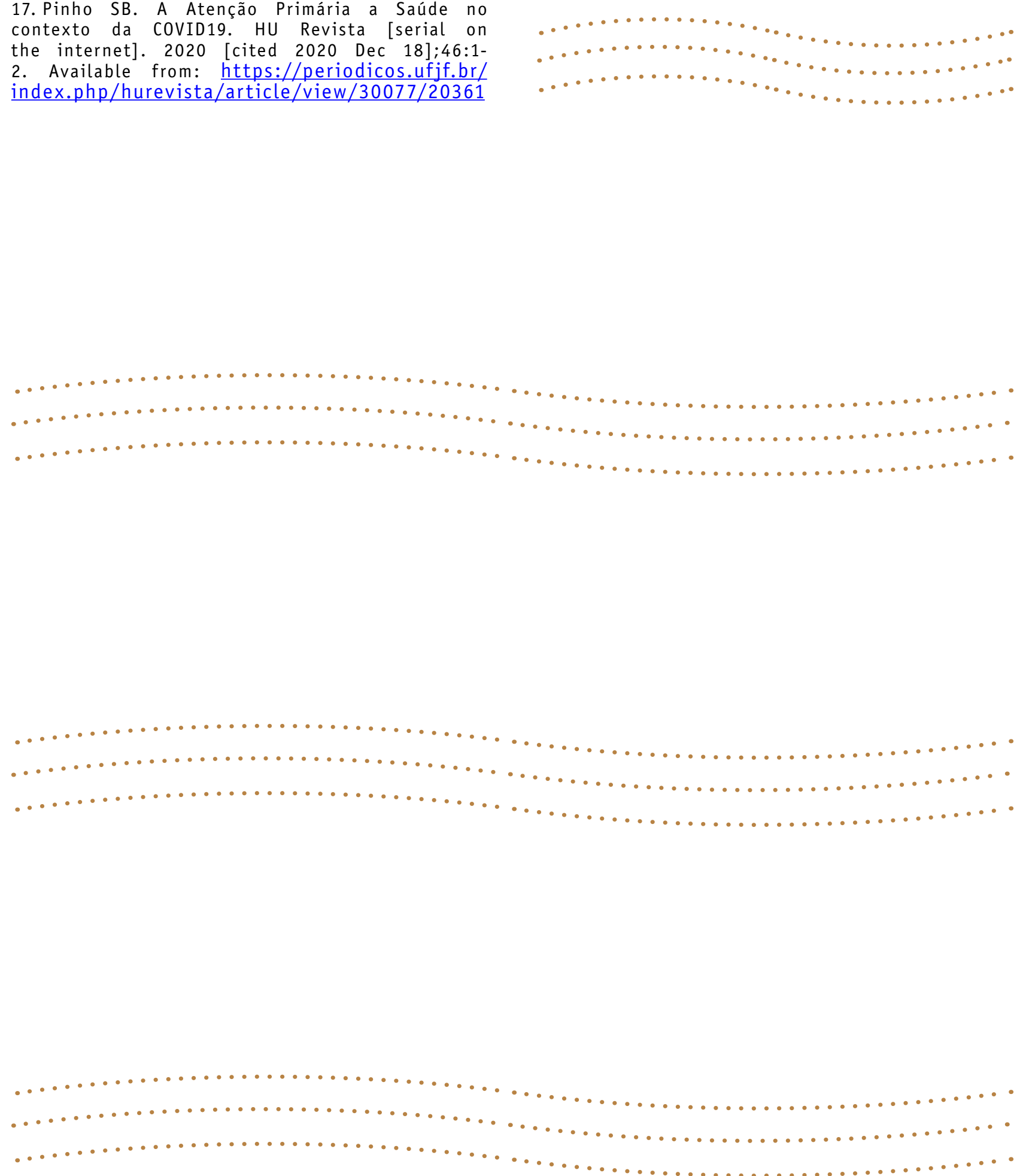